\title{
La regulación de los collares dañinos: avanzando en el bienestar canino
}

\author{
Emma Infante Sentelles
}

Cuando pensamos en el maltrato animal, y nos centramos en los perros, nos vienen a la cabeza dramáticas imágenes de agresiones, de abandono, de confinamiento insalubre y falta de cuidados, pero hay un maltrato cotidiano generalizado en España que crece al ser promocionado por entrenadores no acreditados y por la ignorancia de la fisiología y la etología caninas. Demasiados perros sufren el maltrato diario de ver rodeado su cuello con collares de castigo. Clasificables en collares de pinchos y de ahogo - y con menos frecuencia- de descargas, ya sean eléctricas o de sustancias repelentes como la citronela, estos collares generan daño en el animal. Los collares de pinchos son metálicos, pesados, pero sobre todo, sus púas inciden profundamente en una zona muy vulnerable del perro. No sólo los llevan en una parte muy sensible, si no que a través de la correa muy a menudo estos adminículos ven aumentado su potencial nocivo con los tirones que el dueño propina al perro con ánimo de someterlo, muy frecuentemente, de modo infructuoso. Los collares de ahogo son generalmente sogas metálicas que comprimen el cuello del can cuando este toma una dirección o velocidad distintas a las del propietario. La falta de oxígeno por estrangulación persuade al perro de redirigir sus pasos. La repetición de la experiencia acaba sometiendo al animal a una conducta robótica que es la única que le preserva de la terrorífica sensación de ahogo. Los collares de descarga eléctrica insertan un dentado doble con un voltaje intenso, muy desagradable, que desconcierta, asusta y a veces hiere al animal. La activación del mecanismo suele hacerse por control remoto. Todos estos instrumentos tienen su origen en teorías desfasadas de condicionamiento. En principio, estos collares sólo deberían haber estado en manos de adiestradores profesionales, en periodos reducidos de la educación del animal y cuando la conducta anómala sugiera un peligro propio y ajeno. Estas colleras son baratas, muy accesibles y además crean la fantasía de ejercer un cierto control sobre la víctima aunque sea infringiéndole un daño y potenciando una experiencia incompatible con cuatro de las cinco libertades que sientan las bases del bienestar animal. En 1965 el Farm Animal Welfare Committee (FAWC) dictó la ausencia de malestar, de dolor, de daño y de enfermedad, la facilitación del comportamiento natural y también la ausencia de miedo y estrés como mínimo común a garantizar en nuestro trato con los animales. Todos estos principios están amenazados por algo tan simple y frecuente como los collares de pinchos, de ahogo y de choque.

648.797.17 Euros destinó el Departamento Británico de Alimentación y Asuntos Rurales (DEFRA) entre los años 2007 y 2011 en dos estudios sobre el bienestar de los perros domésticos adiestrados con collares eléctricos. Investigadores de las Universidades de Bristol, de Lincold y el Laboratorio Central de Ciencias desarrollaron experimentos comparando el uso de los collares como parte del entrenamiento canino con técnicas educativas en positivo (mediante recompensas de las conductas deseables). Concluyeron que ante resultados similares la mayoría de los propietarios de perros prefieren el uso de métodos en positivo frente a los aversivos, en este caso, específicamente los collares eléctricos. Si dos técnicas obtienen resultados semejantes pero una de ellas arroja complicaciones y secuelas evidentemente la eficaz, y a la vez inocua, debe prevalecer. También se recogieron datos sobre agresiones secundarias al miedo y el estrés infundidos por las técnicas inapropiadas. Otro dato significativo es que los collares eléctricos generan una ansiedad indiscriminada en los perros que los han sufrido que puede medirse a través del cortisol en su saliva. Se sabe que ante el maltrato la víctima disminuye la confianza en sí misma y, obviamente, en el maltratador. No es este el vínculo que debe unirnos.

Abundando ya en la normativa sobre el uso de este tipo de collares podemos afirmar que ya ha sido impuesta la primera multa por el incumplimiento de la ley que prohíbe el uso de los collares eléctricos en Gales. 3608 euros debe pagar, entre la sanción y las costas, el propietario de un Border Collie que usó con él un collar eléctrico. Aunque los clubes caninos más prestigiosos y la mayoría de asociaciones de educadores caninos acreditados renieguen de estos collares, no está prevista la inmediata abolición en el resto de las islas Británicas. Su uso se restringe entre los menos formados. En Italia una reciente sentencia de la Sección Tercera del Tribunal Penal de Casación dicta claramente: "El collar eléctrico es 
ciertamente incompatible con la naturaleza canina, basándose en la producción de descargas y otros impulsos eléctricos que le provocan distintas reacciones... siendo un adiestramiento que se basa en el dolor, leve o fuerte no importa, incide sobre la integridad psicofísica del perro... produciéndole como efectos colaterales miedo, ansiedad, depresión e incluso agresividad... tal instrumento genera sufrimiento y encarnizamiento innecesarios". Es una sentencia que confirma la legitimidad de la prohibición de su uso según aparece en el Código Penal Italiano. No nos extraña que en Austria y en Suiza los collares de pinchos, de ahogo y eléctricos estén prohibidos pero también en la República Checa están prohibidos. En la vecina Alemania numerosos educadores caninos han unido sus fuerzas para conseguir la sanción de su uso. Debemos destacar el empeño de un colectivo canadiense contra los collares eléctricos. Han conseguido que al menos tres diputados, en tres momentos distintos, solicitasen a la Cámara el fin de la impunidad en su uso y, por supuesto, su comercialización.

En Norteamérica algunos Estados están estudiando la posibilidad de incluir la prohibición del uso de estos collares dentro de la normativa anticrueldad. Existen allí precedentes judiciales en los que se ha dictaminado la peligrosidad de los collares dañinos. Hace más de 30 años la sección correspondiente de la Food and Drug Administration (FDA) pudo comprobar que los collares eléctricos antiladridos se activaban con cualquier sonido intenso, lo que condenaba al animal a descargas continúas que les causaban graves quemaduras. El Centro de medicina Veterinaria (VMC) promovió acciones para la regulación de dichos collares y los fabricantes se vieron obligados a introducir mejoras para hacerlos más selectivos. El tránsito internacional de productos de fabricación no homologable hace que muchos collares carezcan de los mínimos estándares que satisfarían a los reluctantes defensores de su persitencia. Deberían preguntarse los que los patrocinan alegando su inocuidad el hecho de que esté prohibido el uso de los collares eléctricos en personas.

Saltando de nuevo a través del globo terráqueo En Nueva Zelanda los collares de pinchos y ahogo están prohibidos por Orden Gubernamental. En Australia, la mitad de los Estados tienen prohibido de uno u otro modo (venta, posesión y/o uso, con exenciones en virtud de ciertas problemáticas o prescripción veterinaria) uno o todos los collares que llamamos dañinos. El propio gobierno Australiano tiene en la página oficial de su Departamento de Agricultura disponible un estudio que demuestra que los métodos aversivos, en concreto los collares eléctricos son usados con mucha más frecuencia por los entrenadores no acreditados que los que sí lo están. En un estudio que estamos realizando y aún en curso podemos observar que los defensores del uso de estos collares por un lado suelen carecer de formación académica, en sus países la profesión de adiestrador no está regulada y además suelen participar en prácticas que estimulan la agresividad del animal y la competición bien sea el ring francés o lo que llaman el adiestramiento deportivo. Claro está que las empresas que los fabrican y comercializan hacen ímprobos esfuerzos publicitarios para preservar su negocio.

Volviendo a Europa, algunos expertos consultados no ven ninguna necesidad en reclamar una legislación que prohíba los collares de pinchos, de ahogo o eléctricos pues en su país su uso es puntual y se restringe a algunos entrenadores con métodos anticuados. Este sería en caso de Hungría y Rumanía, por ejemplo. En Noruega, o en Suecia algunas personas que trabajan profesionalmente en la educación canina consideran que su uso está condenado a la extinción porque entre otras cosas está mal visto socialmente. En nuestras latitudes, como ya hemos dicho, tenemos un problema con los collares de pinchos y ahogo. Como novedad no podemos dejar de señalar que incluso en España está apareciendo un cierto pudor frente a su uso: ya hay una empresa que comercializa unas fundas para los collares de pinchos, para darles un aspecto más amigable y que nadie formado pueda reprochar su uso. Algunos paseantes se limitan a ocultarlos bajo un pañuelo o bandana. Los collares eléctricos son una epidemia en los países con una arraigada tradición de pastoreo, y de ciudades con hogares unifamiliares y patios extensos pero no aquí. Los collares de pinchos y ahogo (y su versión light los cordinos de fibra trenzada) han visto incrementadas sus ventas como parte de la desinformación generada por programas de televisión conducidos por showmans y entrenadores autodidactas que exigen resultados rápidos sin importar que implique un daño en el animal. Como reconocen algunos usuarios este tipo de collares también son prescritos por algunos profesionales de la veterinaria que ignoran la literatura que describe los daños colaterales que señala la ley italiana. Están reportadas lesiones en la tráquea, en el nervio 
ocular, glaucoma y en el aparato respiratorio sobretodo en perros bracocefálicos. Las radiografías, TACs y necropsias podrían dar cuenta de fisuras y fracturas en la espina cervical y en el atlas secundariamente al uso continuado, u ocasionalmente extremo, de los collares metálicos. Es fácil apreciar el amoratamiento de las mucosas cuando el perro, al estirar, restringe el paso de sangre y oxígeno a la cabeza. Se han podido constatar lesiones cerebrales multifocales por isquemia en un pastor alemán que había sido "entrenado" con collar de choque. Este es un caso muy bien documentado pero alguien puede pensar que puntual. Los datos presentados por Anders Hallgreen, en 1993 en un estudio con más de 400 perros, pudo detectar en el $91 \%$ de ellos las secuelas de los tirones recibidos a través del collar y la correa. En su libro en el que detalla que los problemas de espalda son la causa subyacente de problemas de comportamiento ${ }^{1}$ argumenta la necesidad de generalizar el uso de los arneses.

En definitiva y más allá de valoraciones subjetivas, estamos en condiciones de decir que dada la ausencia de evidencias científicas sobre la eficacia en la modificación de la conducta, especialmente a largo plazo, por el uso de collares dañinos, sumado al elevado potencial de errores o abuso deliberado de los mismos deberíamos cuestionar fabricación, venta y utilización. La ley debe llegar donde no llega el conocimiento y la conciencia ciudadanas. Si queremos cumplir con los preceptos descritos en ordenanzas y decretos en los que se explicita en un inicio que está prohibido maltratar, agredir o afectar psicológicamente a los animales y, más adelante en los artículos dedicados a los perros en la vía pública ir ligados por medio de un collar y una correa o cadena, que no ocasionen lesiones al animal ${ }^{2}$. Así pues en justo cumplimiento de la norma debemos informar, como hacemos, de la amenaza que significa el uso de estos collares y la contravención de la normativa de protección animal vigente que sanciona, con mayor o menor contundencia, el maltrato sobre seres sentientes.

Acabamos con las palabras que el prestigioso veterinario, y profesor del Máster, LLuís Ferrer nos comunicó al respecto: “¿Collar de castigo? Es absolutamente prescindible y cruel. No hay ninguna necesidad de utilizarlo y apoyo las iniciativas destinadas a prohibirlo "

\footnotetext{
${ }^{1}$ HALGREN,A., Problemas de espalda en los perros ( A Coruña, 2010) Kns Ediciones.
}

${ }^{2}$ Ver artículo 24, 2,c. de la Ordenanza Municipal Sobre protección y Tenencia de Animales de Enero de 2004. 